\title{
EL CONGRESO ARGENTINO DE LA HABITACIÓN (1920): UNA INFLEXIÓN EN EL TRATAMIENTO DE LA VIVIENDA COMO PROBLEMA
}

\section{María Guillermina Zanzottera*}

ProHUT - IAA - Facultad de Arquitectura, Diseño y Urbanismo - Universidad de Buenos Aires

$\bowtie$ guillezanzo@gmail.com
Recibido: 2 de diciembre de 2020

Aceptado: 2 de febrero de 2021

DOI: 10.46553/colec.32.1.2021.p55-87

Resumen: Entre el 5 y el 13 de septiembre de 1920 el Primer Congreso Argentino de la Habitación, organizado por el Museo Social Argentino, logró reunir en un mismo espacio al heterogéneo elenco de actores e instituciones que se disputaban protagonismo en la esfera de la problemática habitacional. El examen de los debates que se dieron en las diversas comisiones de ese evento permite observar un punto de inflexión en el tratamiento de la "cuestión de la vivienda" que pasó a incorporarse como tema relevante de las agencias y las agendas públicas.

Palabras claves: Museo Social Argentino; entreguerras; vivienda social; Primer Congreso Argentino de la Habitación

\footnotetext{
* Magister en Ciencias Sociales con mención en Historia Social. Investigadora Principal del IAA-FADU-UBA. Editora de la Serie Tesis del IAA.

Este artículo es el resultado del trabajo que se desarrolla en el marco del Programa de Historia Urbana y Territorial, del Instituto de Arte Americano, IAA-FADU-UBA. Una primera versión del mismo fue discutida la Mesa 98 La Argentina de entreguerras: Estado, política y sociedad en un período de conflicto y transformación (1918-1939), coordinada por Mercedes López Cantera, Noelia Fernández e Ignacio López, en el marco de las XVI Jornadas Interescuelas de Historias y en el Seminario de Crítica del Instituto de Arte Americano e Investigaciones Estéticas "Mario J. Buschiazzo".
} 


\begin{abstract}
Between September 5th and 13th, 1920, the Primer Congreso Argentino de la Habitación, organized by the Museo Social Argentino, managed to bring together in the same place the heterogeneous cast of actors and institutions that were vyng for prominence in the sphere of housing problems. The examination of the debates that took place in various commissions during that event allows us to observe a turning point in the treatment of the "housing issue" that has become a relevant issue for agencies and public agendas.
\end{abstract}

Keywords: Museo Social Argentino; Interwar period; social housing; Primer Congreso Argentino de la Habitación

\title{
I. Introducción
}

En 1920 en un contexto de alta conflictividad social que tenía su centro en la carestía de vida -en el que impactaba fuertemente el aumento del precio de los alquileres- el Museo Social Argentino (en adelante MSA), ${ }^{1}$ institución privada orientada al estudio de los problemas sociales, organizó el Primer Congreso Argentino de la Habitación.

Si bien el tema no era totalmente novedoso, pues desde las últimas décadas del siglo XIX la "cuestión de la vivienda" se presentó como clave explicativa del conflicto social, el particular escenario de fines de la década del diez generó un ambiente propicio para que el MSA convoque con éxito al heterogéneo elenco de actores e instituciones que se disputaban la intervención en la problemática habitacional, logrando establecer una agenda común. Según planteamos en este artículo, el examen de los debates que se dieron en las diversas comisiones del Congreso nos permite observar un punto de inflexión en los modos de pensar y operar sobre la vivienda y ciudad.

1 Sobre el MSA ver: Girbal de Blacha y Ospital (1986), Zimmermann, (1995), Zanzottera (2015) y Becerra (2016). 
En relación a los estudios sobre el habitar y la ciudad, los años veinte se incluyen dentro de un ciclo que va del Centenario a los años treinta, inscripto en un periodo más largo que se extiende de fines del siglo XIX a 1943. Como rasgo característico se puede señalar que la vivienda se construye como problema urbano, social y público en el marco del ideario reformista, para estos años se ponen en marcha conjuntos habitacionales impulsados por grupos católicos, cooperativas y municipios, se sancionan las primeras leyes orientadas a la vivienda social y se crea la primera agencia estatal especializada, la Comisión Nacional de Casas Baratas (en adelante CNCB). En un primer momento, los debates se centraron en las tipologías y paulatinamente se fueron sumando las discusiones en torno de los aspectos técnicos y estilísticos, habilitadas por la incorporación de los arquitectos al elenco de especialistas, que estaba integrado por ingenieros, cientistas sociales, médicos, hombres de negocios y reformadores. En nuestro medio, el tema de la vivienda social en las primeras décadas del siglo $\mathrm{XX}$, fue examinado por diversos estudios que fueron desplazando sus objetos y objetivos en el que hemos identificado tres momentos que responden a temas, problemas y enfoques particulares. Nos interesa mostrar los rasgos distintivos de cada uno de ellos, a los efectos de situar nuestro propio planteo. $^{2}$

Hacia 1984 en el retorno de la democracia, el debate académico local se renueva con los aportes de historiadores, cientistas sociales y arquitectos. El contexto de apertura y reorganización del CONICET y la creación de la Comisión de Hábitat dentro del organismo, permiten consolidar una nueva generación de trabajos centrados en lo urbano y la vivienda. ${ }^{3}$ En esos años prevalecen los estudios sobre los "sectores populares", tributarios de las perspectivas de la "historias desde abajo" -tal como señalan Novick y Favelukes (2020) - que ponían el foco en la problemática de la ciudad desde

\footnotetext{
${ }^{2}$ Los trabajos sobre la historia urbana de Novick (2003) Gorelik (2004) y Novick y Favelukes (2020), los estudios preliminares de los libros de Aboy (2005), Rigotti (2011) y Ballent y Liernur (2014) y el trabajo sobre vivienda de interés social de Ballent (2004b) nos han permitido abordar el estado de los estudios sobre la vivienda en tres momentos. Sin pretensiones de ser exhaustivos nos centraremos en aquellos trabajos que abarcan los años de entreguerras o que por su problemática interpelan directamente a nuestro trabajo.

${ }^{3}$ Ver: Novick y Zanzottera (2019).
} 
el estudio de las condiciones de vida, la participación política y las prácticas asociativas, como puede verse en las varias compilaciones (Armus 1984; Armus y Barrancos 1990; Gutiérrez y Romero 1995). De esta manera, una historia social renovada, en vinculación con los estudios culturales y los debates sobre la modernidad y las formas urbanas dieron lugar a nuevas perspectivas. La consideración de las tipologías, las instituciones, los instrumentos, los modos de habitar y la vivienda pública se presentan como eje de varios trabajos (Liernur 1984; Ballent 2014a y b; Ballent Liernur y Silvestri 1987). Estos intentaron dar cuenta de los procesos de configuración de la ciudad moderna, de los recursos y estrategias de los sectores populares y de las representaciones por detrás de los debates y construcción de la vivienda social.

Una década más tarde, en los años 90, cuando los temas de vivienda social eran desplazados por las ideas del proyecto urbano y el espacio público, los enfoques de la historia política junto con la mirada de los estudios culturales se orientan al estudio de los elencos técnicos, la profesionalización de las disciplinas y sus representaciones, así como a las políticas de vivienda promovidas por el Estado nacional o los municipios (Novick 1992; Rigotti 1996; Ballent 1997; Gorelik [1998] 2004; Paiva 1998 y Sánchez 1998). Y si en los años ochenta la "mirada desde abajo" fue central, en esta instancia se trató de revisar las políticas urbanas y habitacionales "desde arriba" pero sobre todo "desde adentro" del propio Estado.

Desde el inicio del siglo XXI con la reactivación de las políticas de vivienda en Argentina a partir de 2003, y más ampliamente en América Latina, se vuelve a considerar el tema en las agendas de los investigadores. La reedición en 2006 de La vivienda en Buenos Aires. Primeras Jornadas de Historia de la Ciudad de Buenos Aires, publicado en 1985, la publicación en 2011 del libro de Ana María Rigotti Viviendas para los Trabajadores, una versión corregida de su tesis de maestría defendida en 1996, y la aparición en 2014 del libro La casa y la multitud que recoge los trabajos de los últimos veinte de años de Francisco Liernur y Anahí Ballent, reactualizan algunos de los debates sobre la vivienda y la ciudad. Simultáneamente, desde el campo de los estudios urbanos se publican una amplia gama de revisiones históricas referidas a conjuntos habitacionales, al hábitat precario y a las políticas habitacionales (Dunowicz 2000; Kullock 
y Murillo 2010; Bontempo 2010). En ese marco, el ciclo de la primera metropolización, entre fines del siglo XIX y los inicios del siglo XX, fue revisitado desde muy heterogéneas miradas. Entre ellas, nos interesa mencionar los estudios que colocan el acento en la circulación de conocimientos y modelos y en las redes de temas, personas y problemas (Sánchez 2008; Aguilar 2014; Gómez Pintus 2018; Marimon 2017).

Ahora bien ¿qué puede agregar nuestro estudio a lo que ya se sabe? Con este trabajo, sobre esas huellas de libros e investigaciones, nos proponemos restituir las discusiones que se dieron en el Primer Congreso Argentino de la Habitación de 1920. Consideramos que este evento, destacado como un importante "foro" de discusión y debate (Sánchez 2008; Rigotti 2000 y 2011; Liernur y Ballent 2014; Aguilar 2014; Marimon 2017) y examinado en relación al establecimiento del Urbanismo como disciplina en Argentina (Novick 1993 y 1998; Bragos 1994), puede ser pensado como un importante punto de inflexión. En ese sentido, nos interesa rescatar su relevancia en relación a los consensos establecidos, pues en torno a ellos se fue construyendo una nueva representación sobre la vivienda, que estará por detrás de los debates sobre la planificación del territorio, las nuevas herramientas de intervención, la trasformación de las capacidades estatales y la organización de las agencias públicas.

Para desarrollar esos supuestos, presentamos tres interrogantes que estructuran nuestra argumentación. En primer lugar ¿cuáles fueron las condiciones de posibilidad de ese congreso? En relación, y, en segundo lugar, ¿qué rol le cabe al MSA como institución organizadora? Y, finalmente, ¿qué consensos se dirimen en los debates del Congreso?

\section{La vivienda en cuestión: debates nacionales e internacionales}

El 14 de abril de 1920 Enrique Ruiz Guiñazú ${ }^{4}$ propone que el MSA, institución que preside, organice el Primer Congreso Argentino de la

${ }^{4}$ Enrique Ruiz Guiñazú: (1884-1967), era abogado y profesor suplente Economía Política desde 1912 y titular de Economía finanzas y Estadística desde 1914 en la Facultad de Derecho y Ciencias Sociales de la UBA, de las materias Finanzas y Economía Política en Facultad de Ciencias Económicas y de Derecho Privado de la 
Habitación, ofreciendo su "desinteresado concurso" en "la investigación desapasionada de un grave problema nacional, mediante el estudio de la legislación y de los hechos que lo caracterizan, auscultando la opinión publica ilustrada, para borrar en lo posible, las asperezas de los intereses controvertibles" (BMSA 1921, 181). El contexto era oportuno.

En el año 1919 el aumento del precio de los alquileres llega a un punto crítico y toma un lugar central en el debate público. ${ }^{5}$ Esta situación se dio en una coyuntura de caída del salario real y altos índices de desocupación, que tenían como telón de fondo los sucesos de la llamada "Semana Trágica" y la escalada de movilizaciones y huelgas que en los primeros seis meses del año involucraron alrededor de 10.000 trabajadores (Falcón 1996; Falcón y Monserrat 2000; Cantón et al. 2005).

El impacto del alquiler en el presupuesto de la familia obrera venía siendo registrado por Alejandro Bunge ${ }^{6}$ desde principios de la década del diez. ${ }^{7}$ La construcción de esos datos será clave en los debates de la vivienda,

Facultad de Ciencias Jurídicas y Sociales de la Universidad de La Plata. Se desempeñó como Secretario de Hacienda en la Ciudad de Buenos Aires entre 1908 y 1914, como Director del Registro Civil entre 1910 y 1914 y como Presidente de la Revista del Banco Hipotecario Nacional (en adelante RBHN) desde 1918. Fue fundador y Director de la Revista de Economía Argentina (en adelante REA) hasta 1929 y Presidente del MSA entre diciembre de 1918 y febrero de 1921.

${ }^{5}$ Este tema es ampliamente abordado por Marimon (2017).

${ }^{6}$ Alejandro Bunge: (1880-1943) fue un destacado funcionario estadístico, en 1910 fue nombrado Director de la división de Estadísticas del Departamento Nacional del Trabajo (en adelante DNT) y entre 1916 y 1921 ocupó el cargo de Jefe de la Dirección General de Estadísticas de la Nación, dependiente del Ministerio de Hacienda. En 1918 fundó La REA. Entre 1912 y 1916 asumió la dirección de los Círculos Obreros Católicos (González Bollo 1999, 2014).

${ }^{7}$ En primer lugar, entre 1913 y 1914, como Jefe de División Estadística del DNT realiza una serie de Encuestas que le permitían observar el porcentaje del salario que los obreros invertían en el alquiler, que para esos años implicaba un $20 \%$ (Anales 1919, 88; BDNT 1915, 129 -137; BDNT 1916, 201-222). Estos datos eran puestos en relación con las variaciones del precio de los alquileres que monitoreaba esa misma oficina y que desde el año 1917 registra subas desmesuradas (Anales 1919, 88; BDNT 1919, 253). En segundo lugar, desde las páginas de la recientemente fundada REA, en su rol de Director, comienza a publicar, en 1918, los datos de un estudio que de forma privada estaba realizando sobre el IVC (Bunge 1918, 39-63; 1919, 309-32). Profundizará ese trabajo a partir del año 1919 en los Seminarios de Investigación de la Facultad de 
pues la "objetividad" y "neutralidad" de los números le permitió a legisladores nacionales, municipales y la prensa escrita, debatir sobre bases "científicas" la incidencia del precio del alquiler en el aumento del costo de vida (BMSA 1920, 6; Gonzales Bollo 2014, 85).

Desde diversos ámbitos se identificaba el conjunto de causas que habían abonado al encarecimiento de los alquileres en Argentina. En primer lugar se señalaba la paralización de las construcciones que caen en un $50 \%$ en 1915 y tienen su año más crítico en $1917,{ }^{8}$ producto de la crisis económica vinculada a la guerra y de un escenario que se agudizaba por las huelga del gremio de la construcción a lo largo del año 1919 (MCNCB 1919-1920, BMSA 1920, 66). En segundo lugar, se consideraba el costo de los materiales extranjeros, de los fletes y de la mano de obra, y, en relación, se mencionaba la escasez de los materiales nacionales y los trust en artículos como la cal y el ladrillo, según evaluación de los diversos informes de la CNCB (MCNCB 1918-1919 y 1919-1920). Por otro lado, se argumentaba que el aumento de la población urbana y la demanda por nupcialidad, según datos elaborados por el DNT, habían generado una presión sobre la demanda de vivienda, lo que daba como resultado un incremento desmesurado del precio de los alquileres, que se agravaba con el problema del "intermediario inescrupuloso" (BDNT 1919, 254; MCNCB 1921, 17).

Además, la Municipalidad estaba realizando una encuesta sobre los conventillos, inquilinatos y hoteles, esta información era complementada por visitas e inspecciones que llevaba adelante la CNCB y analizadas a la luz de los datos sobre la población obrera y las condiciones de vida construidos por el DNT, lo que permitía señalar otros problemas de la vivienda popular, entre los que se destacaban el hacinamiento, la falta de baños y retretes, la suciedad de cuartos y patios y el mal cubaje de aire (Coll 1919, 225-226, MCNCB 1919-1920). De los estudios y relevamientos

Ciencias Económicas de la UBA (Anales 1919, 511). Esos estudios serán una pieza fundamenta en la elaboración del Índice de Costos de Vida en la República Argentina (IVC), instrumento central en la construcción del aparato estadístico nacional y que lo consagrará en el escenario internacional. Ver: Gonzales Bollo (1999; 2014) y Lanata (2020).

${ }^{8}$ Estimado sobre la base de los registros de permisos de construcción del Departamento de Obras públicas de la municipalidad relativas a los permisos de edificación en el municipio, elaborado en 1919. 
realizados por diferentes oficinas públicas se estimaba que para solucionar el problema de la habitación era necesario construir, solo en la Capital Federal, 50.000 "piezas" o 16.000 casas o departamentos de 3 cuartos (Coll 1919, 229).

El impacto de los números y los datos elaborados por estas instituciones, en consonancia con un momento en el que tema de los alquileres se construye como un problema de la agenda internacional, -del que daban cuenta las manifestaciones populares de Berlín y Gran Bretaña y la sanción de leyes de vivienda como la de Inglaterra de 1919, de Portugal de 1919 y los debates franceses y uruguayos sobre fijación de precios y desalojos (BMSA1920, 9 y 13-16)-, generan un sinnúmero de iniciativas que se solapan y que presentan una amplia variedad de matices.

En enero del año 1919, la CNCB, recientemente conformada, aprueba la licitación de su primera obra la Casa Colectiva Valentín Alsina ${ }^{9}$ y en marzo los planos del Barrio Juan B. Cafferata. ${ }^{10}$ En abril se crea la Asociación Nacional de Inquilinos, que se organiza en Comité por barrios, con el fin de realizar manifestaciones públicas y denunciar los altos precios de alquiler, la baja calidad de las viviendas y la falta de disponibilidad de casas o habitaciones para alquilar. ${ }^{11}$ En mayo, la Segunda Conferencia Argentina sobre profilaxis de la Tuberculosis incorpora como asunto "la vivienda popular" a su programa. En junio los Diputados Rodolfo Moreno (h) y Roberto Pagés, presentan el proyecto de ley sobre fijación del precio de los alquileres en la Capital Federal ${ }^{12}$ que dará lugar a uno de los más importantes debates legislativos de la época. ${ }^{13}$ En septiembre de 1919, con una fuerte campaña, los sectores católicos, nucleados en la Unión Popular Católica Argentina, ${ }^{14}$ organizan la Gran Colecta Nacional Pro Paz Social, que se proponía destinar parte de los fondos recaudados a la construcción

\footnotetext{
${ }^{9}$ La casa Valentín Alsina que constaba de 67 departamento

${ }^{10}$ El Barrio Cafferata que constaba de 97 unidades de 3 dormitorios y 64 de cuatro dormitorios,

${ }^{11}$ Sobre la Asociación Nacional de Inquilinos, ver: E- 385-P-1920 (La Junta Ejecutiva Nacional de la Asociación Nacional de Inquilinos) y Marimon (2017).

12 Ver: Congreso Nacional, Cámara de diputados, Reunión $n^{\circ} 10$, 8va sesión ordinaria, del 11 de junio de 1919:487/490

${ }^{13}$ Al respecto ver: Marimon (2017)

${ }^{14}$ Creada en 1919, sobre la Unión Popular Católica Argentina ver: Ballent (1990).
} 
de mansiones populares. También en septiembre, la reforma de la Carta Orgánica del Banco Hipotecario Nacional (en adelante BHN) habilita la entrega de crédito a los empleados públicos destinados a la construcción o adquisición de vivienda propia y, desde las páginas de su Revista, participa activamente en los debates de estos años. ${ }^{15}$ En abril de 1920, el Intendente de la Ciudad de Buenos Aires, José Cantilo, presenta en la $1^{\circ}$ Sesión Ordinaria una batería de proyectos para contribuir a la solución del problema, entre los que se encontraban: el desarrollo de un plan de construcción de viviendas económicas que implicaba: la expropiación de terrenos, libre importación de materiales de construcción e instalación de hornos municipales de ladrillos; estímulo y facilidades para la edificación particular estableciendo planos tipos a disposición del público; otorgamiento de franquicias para industrias que edifiquen o den en arriendo casas para sus empleados; la construcción de casas para empleados y obreros municipales; la venta de terrenos municipales para empelados de la administración nacional, e iniciativas sobre disposiciones legales de emergencia para contrarrestar la especulación sobre los alquileres, entre otros. ${ }^{16}$

Es en el marco de esa multiplicidad de acciones ${ }^{17}$ que se presentan como un conjunto coral algo desafinado, en el que -como señala Halperín Donghi $(2007,26)$ - "se mezclan muchas voces y ninguna logra emerger como dominante", pero que tiene la virtud de colocar la "cuestión de la vivienda" en el centro de la "cuestión social", que el MSA convoca a todos los actores involucrados a participar del Primero Congreso Argentino de la Habitación. Las dimensiones del problema exigían soluciones urgentes.

\footnotetext{
${ }^{15}$ Sobre el BHN, ver: Ballent (2004a; 2014) y Gómez (2015).

16 Ver: Diario de Sesiones del Consejo Deliberante del 6 de abril de 1920.

${ }^{17}$ Estas acciones fueron ampliamente discutidas y difundidas en la prensa escrita. Ver: Marimon (2017), quien realiza un interesante trabajo sobre la conformación de una opinión publica en relación al problema del precio de los alquileres.
} 


\section{EI Museo Social Argentino y la convocatoria al Congreso}

El MSA fue un instituto privado, fundado en 1911 por un heterogéneo grupo de intelectuales que aspiraron a la articulación de un discurso reformista ${ }^{18}$ sobre los nuevos problemas que afrontaba el país. En ese sentido intentó presentarse como un "Laboratorio" capaz de realizar investigaciones, reunir información y divulgar experiencias que fundamenten "científicamente" la toma de decisiones políticas. La Institución pretendía llenar "un verdadero vacío nacional", en lo que respectaba a la necesidad de un instituto "informador consultivo e intermediario de los problemas sociales" (BMSA 1912, 6). Esta posición los habilitó a promover, a lo largo de su trayectoria, diferentes acciones entre las que se encuentra el evento objeto de este análisis.

Los problemas que abordó ${ }^{19}$ y su aproximación a la Economía Social ${ }^{20}$ tuvieron una estrecha vinculación con las diversas redes que integraron la Dirección y con los debates públicos que se fueron conformando en cada momento histórico. Así, para 1919, en el marco de intervenciones locales e internacionales sobre el problema de la habitación, identificamos una nueva

${ }^{18}$ Sobre el movimiento de reforma ver: Rodger (1998) y Topalov (1999). Sobre el reformismo en Argentina ver: Zimmerman (1998) y Suriano (2000).

${ }^{19}$ Los temas de los que se ocupó el MSA a lo largo de los años fueron los siguientes: a) Problemas Obreros, b) Problemas de familia (incluye los temas sobre la mujer y el niño, la infancia desvalida y el feminismo), c) Instituciones sociales (referente a la descripción y desenvolvimiento de aquellas instituciones adheridas al MSA o evaluadas como importantes por la función que cumplían a nivel social), d) Problemas urbanos y de vivienda, e) Economía Social (nuclea los problemas de la cooperación, la mutualidad y la economía social), f) Temas rurales, g) Educación, h) Temas de actualidad política y económica, i) Temas de inmigración, j) Museo social (incluye memorias de miembros o colaboradores, acciones vinculadas a celebraciones o gestiones institucionales, creación de centros propios, etc.). ver: Zanzottera (2015).

${ }^{20}$ La "economía social" tuvo una trayectoria singular dentro del MSA. En su fundación designaba tanto a una ciencia nueva que abordaba con un método práctico y experimental los problemas que integraban la cuestión social, como a una serie de instrumentos basados en la solidaridad y el asociativismo. En esa línea, los objetivos de la institución serían el estudio de los problemas sociales en el terreno en que estaban ocurriendo y la promoción de diversas asociaciones solidarias como respuesta a esos problemas, para finales de la década del diez remitiría, además, a la mutualidad y la cooperación como herramientas frente al conflicto social. Ver: Zanzottera (2015). 
red, integrada por miembros y colaboradores involucrados directamente en el tema de la vivienda. Entre ellos, podemos mencionar al Presidente de la Institución, Enrique Ruiz Guiñazú, que desde las páginas de la RBHN -del que era su Director-, promovía discusiones sobre esta problemática. Por su parte el Vicepresidente Horacio Beccar Varela, ${ }^{21}$ Presidente de la Junta Nacional de la Unión Popular Católica, participaba de la organización de la "Gran Colecta Nacional". En este evento también estaba involucrado el consejero Alejandro Bunge, quien venía realizando estudios sobre el problema de la vivienda obrera desde su rol de Presidente de los Círculos Obreros, en su función de Director General de Estadística del DNT y desde las páginas de la REA. Asimismo, los consejeros Gregorio Araoz Alfaro, Juan F. Cafferatta, Joaquín S. Anchorena y Enrique Calot desde la CNCB inauguraban, para esos años, una serie conjuntos habitacionales. Por otro lado, identificamos un grupo más difuso, pero que desde diversos ámbitos promovía la práctica asociativa para resolver el problema habitacional.

Es en el contexto de esa red y en el particular escenario del año 20 que, el Museo Social Argentino, nombra una "Comisión Especial" encargada de llevar adelante diversos estudios con el fin de "contar con todos los elementos de juicio necesarios que le permitan contribuir a la solución del problema" (BMSA 1919, 181). ${ }^{22}$ Esta decisión se da un contexto de cambios de estrategias institucionales. Si en un primer momento se había planteado un programa de acciones en el que se destacaban los viajes de estudio y las presentaciones a congresos en el extranjero, la Gran Guerra había puesto en crisis esos objetivos: la realidad local pasa a ocupar el centro de la escena, y estructura los nuevos interrogantes. ${ }^{23}$

${ }^{21}$ Horacio Beccar Varela (1875-1949). Se doctoró en jurisprudencia en 1896 con la tesis Algunas consideraciones sobre nuestro derecho administrativo, profesor suplente en la materia de Economía Política en la Facultad de Derecho y Ciencias Sociales de la UBA.

${ }^{22}$ Estos estudios fueron publicados en el Boletín del año 1920, que se ocupó de forma íntegra informar sobre el problema de la vivienda: El alza de los alquileres, a cargo del Dr. Guiñazú; El saneamiento de la vivienda en Córdoba, a cargo del Dr. Cafferata; El problema de la vivienda. Reforma jurídica Necesaria, a cargo del Dr. Calot y los informes sobre: Los congresos de internacionales de casas baratas, la Legislación argentina; la Legislación extranjera y la Estadística de la habitación.

${ }^{23}$ Ver: Zanzottera 2015 


\section{El Congreso Argentino de la Habitación: la vivienda como problema}

El Congreso fue realizado en Buenos Aires entre los días 5 y 13 de septiembre de 1920. La convocatoria recibió 117 adhesiones de gobiernos, entidades gubernamentales y otras instituciones públicas y privadas —entre las que participaron asociaciones de propietarios y de inquilinos, partidos políticos, bancos, cooperativas, la Unión Industrial Argentina, la compañía de Cemento Portland, diversas sociedades de fomento, Universidades, Centros de profesionales - y 284 adhesiones a título personal.

Este evento era la oportunidad para que el MSA ponga en movimiento una extensa red de contactos nacionales y, en el marco del conflictivo escenario social, se presente como un ámbito neutral en donde puedan trabajar juntos, "y para el bien común, los hombres de las más diversas tendencias" (BMSA 1919, 278). La dirección de la Institución estimaba que este tipo de acciones realizaba "obra de gobierno, ya que vinculan a los hombres y preparan el ambiente, con la colaboración de la prensa, para las reformas anhelada, construyendo las bases para la acción y la legislación necesaria".

Además, para estos años se multiplicaron los encuentros que tuvieron en su centro el problema de la vivienda: en 1919 se llevó a cabo la Asamblea de la Habitación Barata Chilena y la Exposición Belga y en 1920 el Congreso de Panamericano de Arquitectos en Montevideo y el Congreso Interaliado de Londres. Esos foros, en los que se presentaron amplias propuestas y se establecieron criterios de intervención, se constituyeron en un marco propicio que le permitieron al MSA reencontrarse con los temas internacionales desde la agenda local.

Así, la organización del Congreso se articuló alrededor del Informe realizado por la "Comisión Especial" sobre la legislación nacional e internacional y los diversos congresos sobre la temática. En él se identificaba la creciente "intervención estatal en la solución de la problemática de la vivienda", estas afirmaciones eran sostenidas por los estudios realizados por la RBHN, la REA, la CNCB y el DNT, instituciones con las que el MSA tuvo intensos vínculos a lo largo estos años. Sobre esa base se delineó un amplio programa constituido por cinco Comisiones: I) 
Comisión de Legislación; ${ }^{24}$ II) Comisión de Economía; ${ }^{25}$ III) Comisión de Construcción; ${ }^{26}$ IV) Comisión de Municipalismo y Estadística $^{27}$ y V) Comisión de Acción social. ${ }^{28}$ Además se prepararon exposiciones de cuadros y gráficos y visitas a barrios de viviendas.

Las Comisiones estuvieron integradas por especialistas en los temas y se encargaron de estudiar los trabajos recepcionados y de elaborar los despachos correspondientes, cuya discusión permitió presentar las conclusiones aprobadas por la Asamblea General. Los debates fueron trascriptos en las Actas del Congreso y publicadas en un número especial dentro del Boletín institucional en el año 1921. El análisis de las Actas, nos permitió identificar tres líneas de discusiones, que si bien generaron tensiones y matices en las posiciones, fueron transversales a las diversas comisiones: la primera vinculada al nuevo rol del Estado; la segunda relacionada a la especialización técnica y la tercera referida al vínculo entre vivienda y ciudad.

${ }^{24}$ Encargada de las medidas legislativas y administrativas necesarias para para imponer una nueva política respecto a los deberes del Estado, de las provincias y de las municipalidades para resolver la crisis de la habitación; reformas de la legislación de fondo y procesal en lo atingente a la habitación, el Registro de arrendamientos y tarifas de alquileres en locales sujetos a inspección.

${ }^{25}$ Centrada en las medidas financieras más convenientes para felicitar préstamos de construcciones, en las reformas del régimen sucesorio para salvaguardar la pequeña propiedad, en combinación con el seguro de vida, en el sistema para convertir a los obreros y empleados en propietarios, en el programa mínimo de condiciones necesarias a fin de asegurar a la familia su pleno y feliz desarrollo y en la reforma del régimen fiscal.

${ }^{26}$ Examinaba los sistemas de construcción y empleos de nuevos materiales, las casas individuales, colectivas ciudades jardines y estilos, higiene y servicios sanitarios y las mejoras en habitaciones rurales. Finalmente, no se trató el tema de las casas individuales y colectivas lo que trajo algunas controversias.

${ }^{27}$ Centrada en la reglamentación de las extensiones de las ciudades, los espacios libres, barrios fabriles, medios de comunicación y los resultados estadísticos de los últimos 20 años sobre la vivienda urbana y rural.

${ }^{28}$ Que examinaba la acción oficial de las comunas, de las provincias y de la nación, la acción privada individual y colectiva. Esta comisión se centró principalmente en estudios sobre los impuestos. 


\section{IV.1 Nuevo rol del Estado en la problemática habitacional}

El "nuevo" rol del Estado en relación a la vivienda aparece en el Congreso a partir de dos líneas argumentales.

En primer lugar, identificamos un debate relacionado con la regulación Estatal de las relaciones entre los particulares que fue central en la Comisión de Legislación. ${ }^{29}$ Esta Comisión, que se ocupó específicamente de las medidas legislativas y administrativas necesarias para imponer una "nueva" política respecto a los deberes del Estado Nacional, provincial y municipal para resolver la crisis de la habitación, entendía que el Estado debía "tutelar no solo los derechos del propietario" sino también el derecho de los inquilinos, tornándose indispensable la intervención "publica" en el precio de los alquileres, pues los derechos de unos y otros debían ser considerados con “equidad”. En ese sentido el Dr. Enrique Ruiz Guiñazú, Presidente del Congreso y del MSA, mencionaba en la Sesión inaugural que:

si nos detenemos, señores, en las recientes legislaciones extranjeras de emergencia comprobaremos que el Estado, ha creído de su deber participar en la contienda de estos intereses a fin de aminorar los efectos de la ley económica de oferta y demanda, como ha ocurrido en Inglaterra, Francia, Italia, España, Holanda, Bélgica, Uruguay y otros países, en los cuales el sensible desequilibrio entre la población y las habitaciones, ha acentuado la carestía de vida, incitando al poder público a abandonar la actitud meramente expectante o contemplativa de estos fenómenos, para regularlos $\mathrm{y}$ encausarlos en normas de equidad, asumiendo para ellos funciones tutelares. (BMSA 1920, 182)

Estos argumentos estaban sustentados en las doctrinas del economista Gustav Friedrich von Schönberg que estimaba fundamental la intervención del Estado a partir de una legislación especial (BMS 1920, 13). Esta doctrina, por su parte, se encontraba en las bases del proyecto de Casas Para Obreros elaborado por el Instituto de Reformas Sociales de Madrid en 1907, -institución con quien el MSA tenían vínculos desde 1913-, y estaba

${ }^{29}$ Compuestas por el Dr. Leonidas Anastasi, como Presidente y los Dres. Emilio Pellet Lastra, Roberto M. Ortiz y Alejandro M. Unsain, como Secretarios. 
firmado por Adolfo Posadas, -socio honorario de Museo desde 1912-. Si bien, en todo el Congreso no se hace ni una sola mención a ese proyecto, las referencias a Posadas serán explicitas. En esa línea Ruiz Guiñazú afirmará "esas leyes extranjeras, como las proyectadas entre nosotros, no desconocen los principios constitutivos de la propiedad", sino que:

reglamentan el ejercicio de su derecho con un concepto de circunstancias, que en cierto modo importa la elaboración de un "derecho de la habitación", derecho especial por su objeto en el sentido de reconocer y adaptar a nuevos casos las restricciones o limitaciones ya existentes en los códigos civiles, para proyectarlas más extensivamente por motivos colectivos de índoles social. (BMSA 1920, 183)

Por su parte, Besio Moreno, ${ }^{30}$ en el dictamen de la Comisión de Construcción mencionaba que el hombre "habrá alcanzado la liberación efectiva" cuando "el derecho a su educación a su alimento y a su abrigo", dentro del cual la habitación constituía la parte principal-, sean una realidad universal y consentida por todos (BMSA 1920, 330). En relación, la Comisión exigía la aprobación de una legislación sobre la inembargabilidad de la vivienda obrera y la expropiación de terrenos por parte del Estado con destino a la edificación. Sobre este último punto expresaba:

El Estado debe proceder a la expropiación de terrenos baldíos dentro de las ciudades, con destino a la edificación, porque conceptúa antisocial que dada la escasez de habitaciones, haya todavía propietarios que esperen tranquila y cómodamente la valorización por el esfuerzo común de los

\footnotetext{
30 Nicolás Besio Moreno (1879-1962). Ingeniero civil (especialidad hidráulica y estadística). Cursó sus estudios en la Facultad de Ciencias Exactas Físicas y Naturales de la Universidad de Buenos Aires. Docente de las universidades de La Plata y de Buenos Aires. Director de Obras Sanitarios de la prov. de Buenos Aires entre 19031908. Presidente de la Sociedad Central de Arquitectos entre 1915-1917, 1927-1929 y 1933-1937. Del Centro de Ingenieros de La Plata entre 1912-1914 y del Centro Nacional de Ingenieros entre 1914-1916. Dirigió la revista del centro de estudiantes de ingeniería Politécnica entre 1902-1904 y del Centro Nacional de Ingeniería La ingeniería entre 1911-1913. Socio fundador del MSA.
} 
miembros de la colectividad, antes de lanzar al comercio, por así decirlo, su lote de terreno. (BMSA 1920, 211)

Las argumentaciones de esta línea de discusión tenían en cuenta los proyectos que estaban en tratamiento en el Congreso Nacional sobre el congelamiento de alquileres y la suspensión de los desalojos. ${ }^{31} \mathrm{Si}$ bien estos temas tensionaron las posiciones, "el principio de justicia social" que entrañaban permitía que, por ejemplo, el Dr. Díaz Arana, ${ }^{32}$ que consideraba que la ley de alquileres podía tener un efecto contraproducente frenando la construcción de casas, apoyara el despacho de esta Comisión. Díaz Arana, señala qué el concepto clásico de propiedad se estaba "rectificando", lo que podía observarse en la sanción de la ley que autorizaba la apertura de las avenidas diagonales.

Por detrás estaban los desplazamientos del pensamiento jurídico hacia "un nuevo derecho orientado a regular las intervenciones del Estado en los problemas sociales" (Zimmerman 2013, 83). Movimiento al que adherían muchos miembros del MSA y del que el jurista francés León Douguit ${ }^{33}$ era el mayor representante (Zimmerman 2013; Herrero 2014). ${ }^{34}$ En la base de las argumentaciones estaba la idea de la propiedad como "función social" que permitía que, sobre la antigua concepción individualista del derecho, primen las necesidades de la comunidad. Lo que posibilitaba que comience a articularse un "Derecho de la Habitación" que sí bien aún no se constituía

\footnotetext{
${ }^{31}$ Que serían sancionadas en 1921: Leyes No 1156 y 11571

32 Juan José Díaz Arana (1880-1865) graduado de la Facultad de Derecho y Ciencias Sociales de la UBA, profesor suplente de la materia Economía Política desde 1907 y desde 1913 titular de esa materia en reemplazo de Marco Avellaneda. En 1924 fundó el Centro de Estudios de Economía Social y Política en la UBA y sobre esas bases organizó en 1925 Centro de Estudios Cooperativos en el MSA. En 1918 fundó la REA y fue su director hasta 1921. Socio activo del MSA y Presidente entre marzo de 2017 y diciembre de 2018.

${ }^{33}$ En 1911 Leon Douguit había viajado a dar una serie de conferencias a Buenos Aires de la que participaron varios miembros y colaboradores del MSA, como Juan José Díaz Arana, Alejandro Ruso, Rafael Herrera Vegas y Alfredo Palacios (Herrera 2014).

${ }^{34}$ Ese "nuevo espíritu", que aspiraba a transformar los procesos de formación de juristas y abogados, había comenzado tras la huelga de 1903 en la Faculta de Derecho y Ciencias Sociales y culminaría con una propuesta de reforma del plan de estudio (Zimmermann 2013).
} 
en el "derecho a la vivienda" tal y como lo conocemos, reconocía y consagraba limitaciones al derecho de propiedad por motivos de carácter colectivo.

Ahora bien, en segundo lugar, dentro del debate sobre el "nuevo" rol del Estado, identificamos una línea que, en franca oposición a la regulación estatal, estimaba que la normalización del precio de los alquileres ocurriría "naturalmente" con el restablecimiento en el equilibrio de oferta y demanda y, que eso "sucedería cuando la construcción se haya intensificado". Esa línea que se articuló alrededor del informe de la Comisión de Economía, ${ }^{35}$ consideraba indispensable estimular la acción privada a partir de la modificación del régimen tributario, la exención de los derechos de edificación y de los impuestos aduaneros, recomendando asimismo la ampliación de la acción ejercida por el Estado, aumentando los recursos de la CNCB.

La idea de un Estado constructor se asentaba en el carácter "excepcional o de emergencia" de la coyuntura y era apoyada por el Ingeniero Dr. Besio Moreno, el Intendente municipal José Luis Cantilo y del Presidente de la CNCB, Dr. Carlos Coll. La novedad radicaba en la escala de la tarea a realizar, ya que "por lo menos en la Capital" hacía falta construir 15.000 casas, y en menor escala, Córdoba, Bahía Blanca, Rosario, Mendoza, Tucumán estaban "clamando por la misma causa" BMSA, 1920, 270). Ese era un número impactante si tomamos en cuenta que, desde la primera experiencia de habitaciones obreras a fines de 1800, las construcciones realizadas por el Estado Nacional, Municipal, la Cooperativa el Hogar obrero y la filantropía católica, no superaban las 300 unidades. El Diputado Nacional Dr. Cafferata en el discurso inaugural instaba a construir: "hay que construir. Esa es señores delegados la palabra de orden en todos los pueblos civilizados y para ello se votan los millones en Inglaterra, en Francia, en Alemania, en Bélgica, en Italia" (BMSA, 1920: 193). Además, solicitaba que desde la Asamblea se "llame a la puerta del Congreso Nacional, para que no se demoren por más tiempo los recursos, y para que

${ }^{35}$ A cargo de los Dres. Horacio Marcó, Raúl Gonnet, José Barrau y Juan José Díaz Arana. 
las diversas iniciativas presentadas por varios diputados y por el que habla, puedan tener una sanción inmediata". ${ }^{36}$

Ahora bien, frente a una acción individual que se presentaban como "impotente para realizar el programa de una edificación fácil y abundante", la oposición a esta línea argumental se articuló alrededor de la "acción privada colectiva", solicitando el estímulo e impulso de la cooperación. Esto se encontraba en sintonía con la inclinación a la Economía Social del MSA y con las conclusiones sancionadas un año antes en el Congreso de la Cooperación (BMSA 1920, 275). Los beneficios de la solución asociativa a la problemática habitacional eran presentados a partir de la experiencia de sociedades cooperativas adherentes al evento, como El Hogar Obrero, La Casa Popular Propia, De Empleados de Bancos.

\section{IV.2 La especialización técnica y el papel de los arquitectos}

En vinculación, observamos una segunda línea de debate con una fuerte presencia en las discusiones que se generaron a partir de los Despacho de las Comisiones de Construcción, ${ }^{37}$ de Municipalismo y Estadística, ${ }^{38}$-ambas a cargo de ingenieros-y de Economía, en los que se relacionaban el saber especializados sobre la vivienda, la tecnificación constructiva y la profesionalización de la construcción.

Así, por un lado, de la mano de la construcción a gran escala, adquieren relevancia los temas referidos a la coordinación de las tareas y a la centralización de la información. Si en las Comisiones del evento se debatía la necesidad de ampliar la injerencia de la $\mathrm{CNCB}$ o de crear un nuevo

\footnotetext{
36 Ver expedientes: E-2091_2-D-1920 (Rodríguez, Carlos J. - Reformas a la ley de Casas Baratas); E-230-D-1920 (Cafferata, Juan F. - Ampliación a la ley 9.677 de Casas Baratas); E- 232-D-1920 (Tierney, Juan P. - Emisión de bonos con destino a la edificación de casas baratas); E-781-D-1920 (Cafferata, Juan F - Construcción de casas baratas para maestros)

${ }^{37}$ A cargo los Ingenieros Nicolás Besio Moreno, Juan Ochoa, Enrique Marco del Pont y el Arq. Eduardo M. Lanús.

${ }^{38}$ A cargo de los Ingenieros Felipe Meyer Arana, Eduardo Crespo y D. Casimiro Prieto Costa
} 
organismo, ${ }^{39}$ en el Congreso Nacional, se estaban discutiendo proyectos orientados a la ampliación de las funciones y erogaciones de la $\mathrm{CNCB}$, la creación de un Instituto Nacional de Casa para Trabajadores y a la emisión de bonos que dejaba la construcción de vivienda bajo la órbita la Dirección de Arquitectura del Ministerio de Obras Públicas. ${ }^{40}$ En definitiva lo que estaba en juego era a qué dependencia le correspondía la construcción de vivienda y las tensiones alrededor de la efectividad de las acciones de la CNCB. Pero además, se ponía blanco sobre negro en torno a la necesidad de un ente centralizador, ya que se "carecía de datos estadísticos precisos que sirvan de orientación para el estudio del problema de la vivienda" (BMSA 1920, 361). Como vimos, los datos sobre la vivienda se construían desde diversas instituciones entre ellas la Municipalidad, la CNCB, la Dirección de Arquitectura del Ministerio de Obras Públicas, el DNT, pero también el Partido Socialista, la Unión Popular Católica, la Sociedad Central de Arquitectos, la RBHN, la REA, lo que conllevaba la construcción de conocimiento parcializado. En ese sentido, la ausencia de datos positivos respecto a la edificación, las falencias del método utilizado en el empadronamiento de la "propiedad raíz", el "deficiente criterio descriptivo y evaluativo" y la falta de catastro, dificultaban "ejecutar un serio estudio estadístico, como fundamento de ulteriores resoluciones de gobierno" (BMSA 1920, 185). Así, desde la Comisión de Municipalismo y Estadística, se instaban a las facultades de Derecho y de Economía a formar profesionales idóneos en estadística, para que, sobre la base de números precisos, puedan elaborarse estudios "científicos" sobre el problema de la vivienda (BMSA 1920, 361).

En segundo lugar, la necesidad de lograr una construcción económica a partir de estrategias tecnológicas - la imaginación técnica a la que hace

\footnotetext{
39 Esta fue una de las conclusiones principales de la Comisión de Municipalismo y Estadística.

${ }^{40}$ Ver expediente: E-63-PE-1920 (Mensaje y proyecto de ley Casas para empleados, clases y agentes de policía); E-64-PE-1920 (Mensaje y proyecto de ley. Casas para obreros y empleados); E-129-D-1920 (Molina, Victor M. - Creando el "Instituto Nacional de Casas Baratas); E-2091_2-D-1920 (Rodríguez, Carlos J. - Reformas a la ley de Casas Baratas); E-230-D-1920 (Cafferata, Juan F. - Ampliación a la ley 9.677 de Casas Baratas); E- 232-D-1920 (Tierney, Juan P. - Emisión de bonos con destino a la edificación de casas baratas).
} 
referencia Sarlo- toma un rol relevante. Sobre la base del Informe elaborado por la "Comisión especial" se estimaba que los costos de cada vivienda eran de 10.000 pesos, lo que implicaba una erogación de 150.000.000 pesos para llegar a las 50.000 viviendas faltantes solo en la Capital. El ajuste por el salario quedaba descartado a razón del "problema social" que estaba en el centro de la "cuestión de la vivienda", por lo que se apuntó a bajar los costos de los materiales y a la modificación del sistema de constructivo.

En esa línea la Comisión de Construcción instó a que "los poderes públicos y las grandes instituciones" establezcan recompensas de estímulo y premios a aquellas "personas que presenten soluciones consagradas por una práctica adecuada". Recomendando a los técnicos, entidades oficiales, corporaciones y particulares, el estudio de pavimentos y sistema de cloacas internas, la producción mecánica de ladrillos, el ensayo de edificaciones en base de bloques de cemento y cemento armado y la realización simultánea y en conjunto de un gran número de habitaciones, entre otras. Lo que estaba por detrás de los concursos y las patentes, ${ }^{41}$ tan corrientes en estos años, era la posibilidad de imaginar tecnologías alternativas que permitan abaratar los productos, una suerte de innovación en los materiales y en los procesos de producción. Liernur (2014) señala que la Primera Guerra actuó como estímulo a la innovación tecnológica local referidas a sistemas constructivos, que mantuvo un promedio de 30 patentes anuales hasta 1930. En la Comisión de Construcción se presentaron 17 trabajos, de los cuales 12 se referían específicamente a construcción, fabricación y obtención de materiales, en su mayoría eran estudios sobre bloques y coladuras de cemento armando, ladrillos económicos de tierra armada, bloques huecos de mortero y hormigón armado a base de cal.

La Comisión voto a favor de que se realicen ensayos experimentales de los proyectos presentados, pues la mayoría no habían sido probados. Esta recomendación fue puesta en cuestión por dos motivos, en primer lugar, no quedaba claro quién debía realizar las experimentaciones si la Facultad o Sociedad de Ingeniería, el Centro de Arquitectos o los particulares, y, en

\footnotetext{
${ }^{41}$ La oficina Nacional de Patentes de Invención fue creada en 1876 como una sección del Ministerio de Agricultura, sobre el sistema de patentes ver: Liernur (2014) y Bonicatto (2018).
} 
segundo lugar, se temía que la recomendación pueda ser tomada como una patente del producto. Lo que da cuenta de la particular trayectoria de legitimación que tenían ese tipo de proyectos que podían incluir su presentación en folleto, libros, postales, exposiciones, así como el patentamiento en diversos países, como puede verse en el trabajo de Bonicatto (2018) sobre el sistema constructivo creado por Mario Palanti en 1920.

Por último, anudado a estos temas se plantea la figura del especialista. En ese sentido, el Ing. Besio Moreno afirmaba que "la construcción en mano de los técnicos sería beneficiosa para la economía y permitiría hacer las construcciones sobre bases científicas" (BMSA 1920, 349). Se señalaba la poca eficacia técnica y obrera, por lo que los esfuerzos debían orientarse en educar al constructor para que pueda ser un "buen colaborador" de los ingenieros y arquitectos (BMSA 1920, 389). En esa dirección se instaba a que las autoridades nacionales y municipales promulguen leyes y ordenanzas tendientes a asegurar la preparación y los conocimientos generales de los constructores, ya que hasta los años 20 la vivienda podía ser tramitada "sin estar avaladas por la firma de un profesional habilitado" (Sánchez 2008, 200). Si bien esta postura fue criticada como una "moción profesionalista", lo que no estaba en dudas era el lugar central que arquitectos e ingenieros debían adquirir en relación al problema de la vivienda, en sintonía con los debates del Primer Congreso Panamericano de Arquitectos que se realizó en Montevideo unos meses antes y que incorpora la vivienda rural y urbana en su agenda de temas. ${ }^{42}$ Asimismo, la exigencia de una intervención especializada sobre la vivienda legitimaba el pedido urgente de reglamentación de la delimitación de las incumbencias profesionales de arquitectos, ingenieros y agrimensores, reclamo que no se resolverá hasta $1944 .^{43}$

\footnotetext{
${ }^{42}$ Sobre los Congresos Panamericanos de Arquitectos ver: Gutierrez Tatarini y Stagno (2007) y Faggion Novo (2018).

${ }^{43}$ En 1944 el decreto-ley 17946 reglamenta el ejercicio profesional de agrimensores, arquitectos e ingenieros creando sus respectivos Consejos.
} 


\section{IV.3 La vivienda y la ciudad}

Por último, puede observarse la vinculación del problema de la vivienda con la reforma de la ciudad en su conjunto, lo que consideramos se constituye en una tercera línea de discusión que atraviesa el evento. Si en el Congreso de 1910, realizado en Londres, el tema central era el de la city beautiful, de la "ciudad de los monumentos", y las alternativas de la "ciudad jardín”, diez años después la experiencia acumulada con la reconstrucción de posguerra, los manuales y las propuestas, desplazaban los debates (Novick 1998). Los sistemas de los espacios verdes y libres, los modelos de baja densidad, la jerarquización y las redes viales, de transporte $\mathrm{y}$ comunicación, estaban en el centro de la escena.

Por un lado, en la Comisión de Legislación, se plantean los modelos urbanísticos de referencia, ponderando el rol de una acción municipal capaz de descentralizar la población formando "ciudades y barrios-jardines", en espacios aun vacíos de la ciudad o en terrenos públicos dotados de vías de comunicación y de servicios (BMSA 1920, 236). En los que, según señalaba Della Paolera, debían tenerse en cuenta las características de cada zona, ya que, las necesidades de la vida moderna aconsejaban la distribución en barrios con diversificación de actividades, conectados por una red de "arterias" que le otorgarían unidad al conjunto (BMSA 1920, 374). En ese marco el rol de los municipios era fundamental. La reforma de la ley electoral de la ciudad de Buenos Aires, que universalizaba el voto masculino inaugura un nuevo periodo para el gobierno municipal (Landau 2018, 110 111). El ámbito local se transforma en un espacio de participación y definición de políticas, donde las pujas pasaban por responder a los problemas de los barrios (Rigotti 2000, 295). Si bien la municipalidad había ensayado algunas acciones vinculadas a la construcción de vivienda, ${ }^{44}$ las intervenciones propuestas implicaban la reforma de la ciudad en su conjunto.

\footnotetext{
${ }^{44}$ La ley 4824 de 1905 autorizaba a la Municipalidad de la capital para emitir títulos destinado a la construcción de casa para obrero y a la trasferencia de terrenos por parte del PE nacional, esto le permite con la aprobación de un empréstito de 1908 y en terrenos donados por la Sra. Buteler realizar en 1910 en primer grupo de 64 casas para obreros y un segundo conjunto de 116 casa.
} 
El desarrollo del tema sobre "ciudad jardín", ilustrado a partir de una exposición de fotografías y notas gráficas, quedó a cargo del Ingeniero Enrique Nelson, quien en 1915 había viaja a San Francisco como delegado del MSA y del Estado Nacional para organizar la Sección de Economía Social en la Exposición internacional y había tenido contacto directo con esas experiencias. El Ingeniero destacaba el tratamiento que el modelo "ciudad-jardín" -movimiento europeo que en los últimos años se había extendido por diversas latitudes- había recibido en los Estados Unidos. ${ }^{45} \mathrm{La}$ propuesta apuntaba a replicar en el país, de manera más "modesta", las experiencias de "Forest-Hill" y "St. Francis Wood" de San Francisco de California. Sugería construir, dentro del ejido de la metrópolis, "barriosparque" destinados a residencias de "moderado costo", con espacios reservados para escuela, plazas, canchas de tenis, salón de usos múltiples, consultorios médicos, correo, telégrafos, etc. (BMSA 1920, 461). Como modelo local de ese formato, presentaba al barrio "Parque Aguirre" estudiado por Ana Gómez Pintus ${ }^{46}$, ubicado en Acasusso, en un sector arbolado y en un contexto de sectores medios y altos. La idea de "barrio parque" se constituye en la articulación del modelo de Ciudad Jardín de Ebenezer Howard y de los ordenamientos residenciales suburbanos vinculados al parque informal inglés (Gómez Pintus 2013, 18). Si bien desde principios del siglo se venían discutiendo la aplicación de ciertos principios de la "ciudad jardín" a las habitaciones populares, que permitían introducir variaciones al trazado rompiendo con la monotonía de la cuadricula porteña (Ballent 2004a, 81), la novedad radicaba en que la propuesta se insertaba en los debates sobre la expansión de la ciudad.

En relación, se dirimían los temas de normativa edilicia y legislación urbanística, que se hacían eco de la recientemente aprobada en Francia Ley Cornudet de 1920 que obligaba a las ciudades de más de 10000 habitantes a trazar planes reguladores. De hecho, el despacho de la Comisión de Municipalismo y Estadística, que trató específicamente el problema de la reglamentación de extensión de las ciudades, afirmaba que:

\footnotetext{
45 Sobre la circulación del modelo de ciudad jardín ver: Topalov (1999).

${ }^{46}$ Sobre el barrio "Parque Aguirre" ver: Gómez Pintus (2013).
} 
la formación de nuevas aglomeraciones urbanas debía estar reglamentada por disposiciones precisas que interpreten los progresos alcanzado en el arte de construir ciudades a fin de que estas resulten salubres cómodas y estéticas debiendo proyectarse su trazado en base a criterio moderno y previendo ampliamente las exigencias del futuro. (BMSA 1920, 358)

Las ciudades debían ser planificadas. La ampliación y mejoramiento de las "aglomeraciones urbanas" debía llevarse adelante por medio de planos reguladores, "a fin de que el progreso de las comunas se efectúe de acuerdo al trazado científico" (BMSA 1920, 359). En esa línea Della Paolera, - que publicaba en 1920 en la revista de Ingeniería su texto sobre aglomeración bonaerense que anticipa estas ideas-, insta a que el "Congreso se dirija a los poderes públicos de toda la República aconsejando el estudio de las medidas legislativas a tomarse con el objeto de confeccionar planos de saneamiento, extensión y embellecimientos de las ciudades y los pueblos de todo el país" (BMSA 1920). Besio Moreno, por su parte, resalta un proyecto del Arquitecto Luis A. Broggi sobre la necesidad de constitución de una "Junta Estética Edilicia" que tenga a cargo el estudio y contralor de las construcciones urbanas para salvar la ausencia de reglamentaciones que precisen y orienten la construcción de nuevas ciudades y la ampliaciones de las existentes hacia ideas modernas (BMSA 1920, 478).

La "ciencia" le otorgaba respaldo al control de la expansión urbana y la intervención de la ciudad, por detrás de estas discusiones estaba el surgimiento de una nueva disciplina: el urbanismo. La solución de los problemas que implicaba la formación y desarrollo de las "aglomeraciones urbanas" requería también, de "profesionales especializados, poseedores de múltiples conocimientos y dotados de temperamento de artista" (BMSA 1920, 362). En manos de la "acción oficial" quedaba el dictado de disposiciones "en armonía con los grandes adelantos alcanzados por el moderno arte de construir ciudades", capaz de estimular un "ambiente propicio" para el desarrollo de esta nueva profesión.

En ese contexto, la ciudad comienza a ser pensar desde la vivienda, pero al mismo tiempo, la vivienda se presenta como una pieza de una problemática más amplia, una ciudad que hay que ordenar y regularizar "de acuerdo a la ciencia moderna", compartida por los expertos que conocen de 
trazado urbano, de salubridad, de gestión, que van a ir instalándose en la administración.

\section{Reflexiones finales}

Con este trabajo, nos propusimos restituir las discusiones que se dieron en el Primer Congreso Argentino de la Habitación de 1920, organizado por el MSA, ya que consideramos que ese evento puede ser pensado como un importante punto de inflexión.

Retomando los interrogantes de la introducción podemos plantear un par de cuestiones.

En primer término, a la sombra de la Primera Guerra Mundial, en un contexto atravesado por la crisis económica y social, el aumento del precio de los alquileres, -dato que venían siendo construidos y registrados desde diferencias ámbitos institucionales públicos y privados-, tiene un fuerte impacto. Alrededor del problema de los alquileres se generan diversas iniciativas que presentan una amplia variedad de matices, y que logran colocar la "cuestión de la vivienda" en el centro de la "cuestión social". En ese escenario el MSA, una institución privada orientada al estudio de los problemas sociales, propone realizar el Primer Congreso Argentino de la Habitación. La organización del evento se da en un momento de cambio de estrategias institucionales y en el marco de las nuevas redes vinculadas al tema de la vivienda.

En segundo término, la convocatoria al Congreso, en línea con una serie de eventos internacionales, les permite al MSA poner en movimiento una extensa red de contactos nacionales y tomar visibilidad en la resolución de un problema que estaba en el centro de los debates públicos, habilitando un espacio de convergencia para un heterogéneo elenco actores e instituciones que se disputaban la intervención en la problemática habitacional.

Por último, y si bien en lo especifico, las discusiones sobre casas de venta o de alquiler, colectivas o individuales, con localización en el centro o en las periferias de la ciudad, -dilemas que atraviesan la historia de la vivienda social-, se presentaron sin soluciones univocas. En contraste, la necesidad de procurar técnicas constructivas innovadoras, la especialización de los profesionales a cargo de su producción, la relación entre la vivienda y la 
ciudad y, sobre todo, el nuevo rol de los poderes públicos fueron algunas de las cuestiones consensuadas.

Los consensos establecidos, transversales a las diversas comisiones del Congreso, nos permitieron identificar un punto de inflexión, que posibilitará la construcción de una "nueva" representación sobre la vivienda que irá configurando el eje de los debates de los años siguientes. En ese sentido, el Congreso se presenta como un interesante prisma para mira los años veinte.

\section{Referencias}

Aboy, Rosa. 2005. Viviendas para el pueblo. Espacio urbano y sociabilidad en el barrio Los Perales, 1946-1955. Buenos Aires: FCE.

Aguilar, Paula. 2014. El hogar como problema y como solución: una mirada genealógica de la domesticidad a través de las políticas sociales. Argentina, 1890-1940. Ciudad Autónoma de Buenos Aires: Ediciones del CCC.

Armus, Diego (comp.). 1984. Sectores populares y vida urbana. Buenos Aires: CLACSO. Buenos Aires.

Armus, Diego y Dora Barrancos (comp.). 1990. Mundo urbano y cultura popular. Estudios de historia social Argentina. Buenos Aires: Sudamericana.

— 1997. "Las huellas de la política: arquitectura, vivienda y ciudad en las propuestas del peronismo. Buenos Aires, 1946-1955". Tesis de doctorado. Facultad de Filosofía y Letras.

http://repositorio.filo.uba.ar/handle/filodigital/2760

Ballent, Anahí. 2004a. "Ciudad jardín". En Diccionario Histórico de Arquitectura, Hábitat y Urbanismo en Argentina, dirigido por Liernur y Aliata. Buenos Aires: Clarín.

. 2004b. "Interés social, vivienda de". En Diccionario Histórico de Arquitectura, Hábitat y Urbanismo en Argentina, dirigido por Liernur y Aliata, págs. 176-187. Buenos Aires: Clarín.

2014a. "Socialismo, vivienda y ciudad. La cooperativa El Hogar Obrero". En La casa y la multitud: vivienda, política y cultura en la Argentina moderna, editado por Liernur y Ballent. Buenos Aires: Fondo de Cultura Económica. 
2014b. "La Iglesia y la vivienda popular: La Gran Colecta Nacional de 1919”. En La casa y la multitud: vivienda, política y cultura en la Argentina moderna, editado por Liernur y Ballent. Buenos Aires: Fondo de Cultura Económica.

. 2014c. "Instituciones y planes, del Banco Hipotecario Nacional al fondo Nacional de la Vivienda". En La casa y la multitud: vivienda, política y cultura en la Argentina moderna, editado por Liernur y Ballent. Buenos Aires: Fondo de Cultura Económica.

Ballent, Anahí y Francisco Liernur (comp.). 2014. La casa y la multitud: vivienda, politica y cultura en la Argentina moderna. Buenos Aires: Fondo de cultura económica.

Ballent, Anahí, Francisco Liernur y Graciela Silvestri. (1987) 2014. "Una discusión sobre el conjunto los andes". En La casa y la multitud: vivienda, política y cultura en la Argentina moderna, editado por Liernur y Ballent. Buenos Aires: Fondo de Cultura Económica.

Banco Hipotecario Nacional. 1986. Balance de un siglo (1886-1986). Buenos Aires BHN.

Becerra Solá, Malena. 2016. "El Museo Social Argentino (1910-1930) cuestión social y redes internacionales de reforma”. Tesis doctoral, Facultad de Filosofía y Letras Madrid.

Bonicatto, Virginia. 2018. "Razón, economía y técnica. El sistema constructivo Palandomus y su efímera aplicación en viviendas". Estudios Del hábitat 16 (2). https://doi.org/10.24215/24226483e055

Bontempo, Luis. 2010. Umbrales de un siglo. Una historia de la vivienda social en la Argentina. De los conventillos al Plan Federal. Buenos Aires: Ministerio de Planificación Federal

Bragos, Oscar. 1994. "El Museo Social Argentino y la formación y difusión de las ideas del urbanismo". En Seminario Internacional. Los orígenes de las políticas urbanas modernas en América Latina 1900-1940. Río de Janeiro.

Bunge, Alejandro. 1918. "Costo de la vida en la Argentina, de 1910 a 1917”. Revista de Economía Argentina 1 (1): 39-63.

Cantón, Dario, José Luis Moreno y Alberto Ciria. 2005. Historia Argentina 6: La democracia constitucional y su crisis. Paidós. Buenos Aires. 
Cirvini, Silvia. 2000. Nosotros los arquitectos: campo disciplinar y profesión en la Argentina moderna. Buenos Aires: Zeta.

Coll, Carlos. 2019. "Casas para Obreros". BMSA, Tomo VIII: 209-229.

Dunowicz, Renée. 2000. 90 años de vivienda social en la Ciudad de Buenos Aires /Programa de Mantenimiento Habitacional. Centro de Estudios del Hábitat y la Vivienda, Secretaria de Investigación de Ciencia y Técnica, Facultad de Arquitectura, Diseño y Urbanismo, Universidad de Buenos Aires.

Dunowicz, Renée y Fernando Villaveirán. 2013. El Hogar Obrero. Un siglo de vivienda cooperativa. Instituto Argentino de Investigaciones de Economía Social. Buenos Aires.

Faggion Novo, Leonardo. 2018. "O lugar da arquitetura no império da técnica: redes e projetos profissionais nos Congressos Pan-Americanos de Arquitetos (1920-1930)". Revista Brasileira de História da Ciência 11 (1): 141-154.

Falcón, Ricardo y Alejandra Monserrat. 2000. "Estado, empresas, trabajadores y sindicatos". En Democracia, conflicto social y renovación de Ideas (1916-1930). Nueva Historia Argentina Tomo VI, págs. 151194. Buenos Aires: Sudamericana.

Girbal de Blacha, Noemi y María Silvia Ospital. 1986. "Elite, cuestión social y apertura política en la Argentina (1910-1930): La propuesta del Museo Social Argentino". Revista de Indias XLVI (178): 609-625.

Gómez Pintus, Ana. 2018. Las formas de la expansión 1910-1950. Buenos Aires: Diseño Editorial, Universidad Nacional de La Plata,

Gómez, Juan Lucas. 2016. "Un país por construir. Las políticas del Banco Hipotecario Nacional durante el primer peronismo, 1946-1955". Ponencia presentada en el XI Congreso Brasileiro de História Económica, Vitória.

González Bollo, Hernán. 1999. “Ciencias sociales y sociografía estatal: tras el estudio de la familia obrera porteña, 1899-1932”. Estudios Sociales 16 (19): 19-39.

2014. La fábrica de las cifras oficiales del Estado argentino (18691947). Bernal: Universidad Nacional de Quilmes.

Gorelik Adrián. (1998) 2004. La Grilla y el Parque. Espacio Público y cultural urbana en Buenos Aires, 1887-1937. Universidad Nacional de Quilmes. 
2004 "Historiografía Urbana". En Diccionario Histórico de Arquitectura, Hábitat y Urbanismo en Argentina, dirigido por Liernur y Aliata, págs. 172-183. Buenos Aires: Clarín.

Gutiérrez, José Luis y Luis Alberto Romero (comp.). 1995. Sectores populares y cultura política. Buenos Aires en la entreguerra. Buenos Aires: Sudamericana.

Gutiérrez Ramón, Jorge Tatarini y Rubens Stagno. 2007. Los Congresos Panamericanos. Apuntes para la trayectoria de la arquitectura en Iberoamérica. Congresos Panamericanos de Arquitectos 1920-2000. Buenos Aires: CEDODAL

Halperín Donghi, Tulio. 2007. Vida y Muerte de la Republica Verdadera. Buenos Aires: EMECE

Herrera, Carlos Miguel. 2014. "Léon Duguit en Buenos Aires: sociabilidad y política en la recepción de una teoría jurídica”. Problema Anuario de Filosofía y Teoría del Derecho 8: 147-177.

http://www.scielo.org.mx/scielo.php?script=sci_arttext\&pid=S200743872014000100006\&lng=es\&tlng=es

Kullock y Murillo. 2010. Vivienda Social en Argentina. Un siglo de estrategias espontáneas y respuestas institucionales 1910-2010.

Lanata Briones, Cecilia T. 2020. "Una Nueva estimación Del índice Del Costo De Vida, Argentina 1912-1932”. Boletín Del Instituto De Historia Argentina Y Americana Dr. Emilio Ravignani 53.

https://doi.org/10.34096/bol.rav.n53.8006.

Landau, Matías. 2018. Gobernar Buenos Aires, ciudad, política y sociedad del siglo XIX a nuestros días. Buenos Aires. Prometeo libros

Liernur, Francisco. 1984. "Buenos Aires. La estrategia de la casa autoconstruida". En Sectores populares y vida urbana, compilado por Armus, págs. 107-122. Buenos Aires: CLACSO.

. 2008. Arquitectura en la Argentina del SXX La construcción de la Modernidad. Fondo Nacional de la Artes, Buenos Aires.

. 2014a. "Aspectos de la dimensión técnica. Una visita a la oficina de patentes de invención”. En La casa y la multitud: vivienda, política y cultura en la Argentina moderna, editado por Liernur y Ballent. Buenos Aires: Fondo de Cultura Económica.

—. 2014b. "Radicar y controlar. La estrategia de la casa autoconstruida". En La casa y la multitud: vivienda, politica y cultura en 
la Argentina moderna, editado por Liernur y Ballent. Buenos Aires: Fondo de Cultura Económica.

. 2014c. "El rol inicial del Estado. La Comisión Nacional de Casas Baratas". En La casa y la multitud: vivienda, política y cultura en la Argentina moderna, editado por Liernur y Ballent, págs. 195-213. Buenos Aires: Fondo de Cultura Económica.

Marimon, Martin. 2017. "The housing question in Buenos Aires, 19001925. Reformism, technical imagination, and public opinion in an expanding metropolis". Dissertation presented to the Faculty of Princeton University.

Novick Alicia. 1992. "Técnicos locales y extranjeros en la génesis del Urbanismo Argentino. Buenos Aires, 1880-1940”. Revista AREA UBAFADU

_. 1993. "El Museo Social Argentino. La ciudad desde el Campo". En Seminario de Critica - IAA 46.

http://www.iaa.fadu.uba.ar/publicaciones/critica/0046.pdf . 1998. "Le Musée social et l'urbanisme en Argentine (1911-1923)".

En Le Musée social en son temps. París: Presses de 1'Ecole Supérieur. . 2003. "El urbanismo en las historias de la ciudad". Registros. Revista De Investigación Histórica 1: 6-26.

https://revistasfaud.mdp.edu.ar/registros/article/view/374

- 2008. "La ciudad como objeto de estudio y acción. Higienistas, ingenieros, arquitectos e instrumentos de planificación y gestión en Buenos Aires". Registros 5: 105-118.

Novick, Alicia y Favelukes. 2020. Derivas de la historia urbana. Libros sobre Buenos Aires. En prensa.

Novick Alicia y María Guillermina Zanzottera. 2019. "La emergencia de los arquitectos como 'investigadores profesionales' en estudios urbanos. Algunas hipótesis de trabajo". Revista A\&P CONTINUIDAD 6 (11): 60 69. https://www.ayp.fapyd.unr.edu.ar/index.php/ayp/article/view/229

Paiva, Veronica. 1997. "Entre miasmas y microbios: la ciudad bajo la lente del higienismo. Buenos Aires 1850-1890" en AREA 4 (Agenda de Reflexión en Arquitectura), SICyT-FADU-UBA.

Rigotti, Ana María. 1996. "El expediente urbano en los primeros planes argentinos". Documento de Trabajo 2. Seminario Internacional Vaquerías. 
2000. "La ciudad y la vivienda como ámbito de la política y la práctica proyectual”. En Democracia, conflicto social y renovación de Ideas (1916-1930). Nueva Historia Argentina Tomo VI, editado por Falcón. Buenos Aires: Sudamericana.

- 2011. Viviendas para los trabajadores. El municipio de Rosario frente a la cuestión social. Rosario: Protohistoria ed. Colección Crónicas Urbanas.

Sánchez Sandra. 2008. El espacio doméstico en Buenos Aires: 1872-1935. Concepciones, modelos e imaginarios. Buenos Aires.

Sarlo, Beatriz. 1992. La imaginación técnica. Sueños modernos de la cultura argentina. Buenos Aires: Nueva Visión.

Sorda, Gabriela. 2018. "El Hogar estable. Discurso, gestión y obras de la Comisión Nacional De Casas Baratas (1915-1943)". Universidad de Buenos Aires Facultad de Arquitectura, Diseño y Urbanismo.

Topalov, Christian. 1999. "Los "reformadores" y sus redes: el desafío de un objeto de estudio". En Laboratoires su nouveau siècle. París: EHESS.

Zanzottera, María Guillermina. 2015. "Actores, redes y estrategia de la reforma social. El Museo Social Argentino (1911-1926)". Tesis de maestría, UNLu.

2018. "La vivienda en disputa. Debates, actores y representaciones en el Primer Congreso Argentino de la Habitación (1920)". Seminario de Crítica del Instituto de Arte Americano e Investigaciones Estéticas "Mario J. Buschiazzo" 225. http://www.iaa.fadu.uba.ar/?p=10993

Zimmermann, Eduardo. 1995. Los liberales reformistas. La cuestión social en la Argentina. Buenos Aires: Sudamericana.

—. 2013. “'Un espíritu nuevo': la cuestión social y el Derecho en la Argentina (1890-1930)." Revista de Indias 73: 81-106. http://revistadeindias.revistas.csic.es/index.php/revistadeindias/article/v iewFile/918/991

Zimmermann, Eduardo y Mariano Plotkin. 2012. Los saberes del Estado. Buenos Aires: Edhasa.

\section{Fuentes}

Boletín Departamento Nacional de Trabajo. 1915. Anuario Estadístico del Trabajo 1913: Vivienda Obrera. Recursos y Gastos, Nº 30. 
Boletín Departamento Nacional de Trabajo. 1916. Anuario Estadístico del Trabajo 1914: Recursos gastos y vivienda de la familia obrera, $\mathrm{N}^{\circ} 33$.

Boletín Departamento Nacional de Trabajo. 1919. Apéndice vivienda obrera en $1918, \mathrm{~N}^{\circ} 42$.

Boletín del Museo Social Argentino. 1912, Tomo I

Boletín del Museo Social Argentino. 1917, Tomo VI

Boletín del Museo Social Argentino. 1918, Tomo VII

Boletín del Museo Social Argentino. 1919, Tomo VIII

Boletín del Museo Social Argentino. 1921. Primer Congreso Argentino de la Habitación, Tomo IX, año 1920, Nº 96.

Boletín del Museo Social Argentino. 1921. El problema de la Habitación, Tomo IX, No 95

Boletín del Museo Social Argentino. 1912, Tomo I

Boletín del Museo Social Argentino. 1917, Tomo VI

Boletín del Museo Social Argentino. 1918, Tomo VII

Boletín del Museo Social Argentino. 1919, Tomo VIII

Bunge Alejandro. 1919. "Costo de la vida en la Argentina. Sus variaciones de 1910 a 1918”. Revista de Economía Argentina, 3 (16), 309-32.

Congreso Nacional. 1919. Debates Legislativos. Comisión especial por el abaratamiento de la vida. Cámara de diputados, Reunión n¹0, 8va sesión ordinaria, del 11 de junio de 1919, 487/490

Facultad de Ciencias Económicas. 1919. Anales de la Facultad de Ciencias Económicas

Facultad de Ciencias Económicas. 1921. Investigaciones de Seminarios, vol II, Buenos Aires, Talleres gráficos

Memorias de la Comisión Nacional de Casas Baratas años: 1918-1919, 1919-1920, 1920-1921-1923-1924

Expedientes del Patrimonio Legislativos. Recuperados de: https://apym.hcdn.gob.ar/

Expediente $\mathrm{n}^{\circ}$ 213-P-1920 (Asociación pro mejoramiento de la vida Solicita la pronta sanción de los proyectos sobre abaratamiento de la vivienda).

http://docs.google.com/gview?url=http://apym.hcdn.gob.ar/uploads/exp edientes/pdf/213-p-1920.pdf\&embedded=true 
Expediente n $^{\circ}$ 385-P-1920 (La Junta Ejecutiva Nacional de la Asociación Nacional de Inquilinos).

http://docs.google.com/gview?url=http://apym.hcdn.gob.ar/uploads/exp edientes/pdf/385-p-1920.pdf\&embedded=true

Expediente $\mathrm{n}^{\circ}$ 63-PE-1920 (Mensaje y proyecto de ley Casas para empleados, clases y agentes de policía).

https://apym.hcdn.gob.ar/uploads/expedientes/pdf/63-pe-1920.pdf

Expediente $\mathrm{n}^{\circ}$ 64-PE-1920 (Mensaje y proyecto de ley. Casas para obreros y empleados). https://apym.hcdn.gob.ar/uploads/expedientes/pdf/64-pe1920.pdf

Expediente $\mathrm{n}^{\circ}$ 129-D-1920 (Molina, Víctor M. - Creando el "Instituto Nacional de Casas Baratas).

https://apym.hcdn.gob.ar/uploads/expedientes/pdf/129-d-1920.pdf

Expediente n²091_2-D-1920 (Rodríguez, Carlos J. - Reformas a la ley de Casas Baratas).

http://docs.google.com/gview?url=http://apym.hcdn.gob.ar/uploads/exp edientes/pdf/209_1_2-d-1920.pdf\&embedded=true

Expediente $n^{\circ}$ 230-D-1920 (Cafferata, Juan F. - Ampliación a la ley 9.677 de Casas Baratas).

http://docs.google.com/gview?url=http://apym.hcdn.gob.ar/uploads/exp edientes/pdf/230-d-1920.pdf\&embedded=true

Expediente $\mathrm{n}^{\circ}$ 232-D-1920 (Tierney, Juan P. - Emisión de bonos con destino a la edificación de casas baratas).

http://docs.google.com/gview?url=http://apym.hcdn.gob.ar/uploads/exp edientes/pdf/232-d-1920.pdf\&embedded=true

Expediente $\mathrm{n}^{\circ}$ 781-D-1920 (Cafferata, Juan F - Construcción de casas baratas para maestros).

https://docs.google.com/gview?url=http://apym.hcdn.gob.ar/uploads/ex pedientes/pdf/781-d-1920.pdf\&embedded=true 